\title{
Mössbauer studies on an AISI 1137 type steel
}

\author{
E GÜLER* and H AKTA ${ }^{a}$ \\ Department of Physics, Faculty of Arts \& Science, University of Kýrýkkale, 71450 Kýrýkkale, Türkiye
}

MS received 28 May 2005; revised 18 April 2006

\begin{abstract}
An AISI 1137 type medium carbon steel was studied by means of scanning electron microscopy and Mössbauer spectroscopy. This steel in as received state at room temperature was ferritic. Different heat treatments on related steel exhibited different microstructures such as pearlite and bainite. Also magnetism of these product phases was determined as $32.7 \mathrm{~T}$ and $32.6 \mathrm{~T}$ relatively where ferromagnetism of ferritic phase in as received state was 33.05 T. Mössbauer parameters such as isomer shifts and \% volumes were also determined before and after transformations.
\end{abstract}

Keywords. Steel; physical properties; pearlite; bainite; Mössbauer spectroscopy.

\section{Introduction}

Over the past few decades, interest has been focused on steels because of their technological importance (Nishiyama 1978), which were most widely used and least expensive, in both industry and technology. However, there are thousands of different steel compositions currently available around the world. As a consequence of above situation in a general manner, the more commonly used steels are classified into three main subclasses such as low carbon steels, medium carbon steels and high carbon steels according to their compositions. Low carbon steels have a carbon content of less than $0.2 \%$ while medium carbon steels have a carbon content between $0.2 \%$ and $0.5 \%$ and high carbon steels have a carbon content above $0.5 \%$ (Callister 2003). On the other hand, depending upon the heat treatment, composition, quenching etc steels exhibit different product phases such as martensite (Umemoto et al 1993; Xiaoyan and Nanju 1996; Ou et al 2003), bainite (Enomoto and Tsubakino 1991; Ohmori and Maki 1991; Bhadeshia 1992), ferrite and also pearlite (Thewlis 2004). All of these phases have various physical properties which are also important for engineering materials. Exemplary, below $0.8 \%$ carbon content the matrix phase is ferrite; an interstitial solution of carbon in iron (Moffat 1967) has a $b c c$ crystal structure and a ferromagnetic character at room temperature (Nishiyama 1978).

From a physical point of view the properties of materials depend on their preparative techniques, i.e. on heat treatment, fast or slow cooling, mechanic deformation, corrosion, aging, irradiation of particles, alloying etc. All these various influences may affect the arrangement of atoms and thus their interaction properties, which consequently influence

\footnotetext{
*Author for correspondence (emre71@email.com)
}

electric or heat conductivity, magnetism, elasticity, density, reactivity, etc.

Since the Mössbauer spectrum is sensitive to changes in electron density, electric field gradient, magnetic field, with respect to absorbed or emitted $\gamma$-rays, and to changes of the mean square displacement (Debye-Waller factors) of the Mössbauer isotope, it is obvious that Mössbauer spectroscopy may serve as a useful tool for the investigation of metals and alloys. Hence the application of Mössbauer spectroscopy in physical metallurgy is a rapidly growing field. Also Mössbauer spectroscopy is a useful technique which determines the magnetism of both austenite and other phases (Gütlich 1978; Gavriljuk et al 2000; Haseeb et al 2001) with their transformation volumes before and after transformations. The aim of the present study is to investigate the magnetism and microstructures of the phase transformations in an AISI 1137 type steel under different conditions.

\section{Experimental}

An AISI 1137 type medium carbon steel was used in this study. The chemical composition of the steel is given in table 1.

For the purpose of microstructural examination, first a thin foil of this steel was mechanically cut from the bulk sample of this steel and also mechanically thinned in as received state to observe ferritic phase and determine its magnetism (sample A). However, another sample was homogenized at $1000^{\circ} \mathrm{C}$ for $1 \mathrm{~h}$ in a quartz tube and quenched into liquid nitrogen $\left(-196^{\circ} \mathrm{C}\right)$ by fracturing the quartz tube (sample B). Another new bulk sample of the same steel was homogenized at $1000^{\circ} \mathrm{C}$ for $1 \mathrm{~h}$ in another quartz tube and quenched into room temperature water by fracturing the quartz tube (sample C). Two slabs were cut 
Table 1. Chemical composition (wt \%) of a commercial AISI 1137 type steel.

\begin{tabular}{lccccccc}
\hline $\mathrm{C}$ & $\mathrm{Mn}$ & $\mathrm{Si}$ & $\mathrm{P}$ & $\mathrm{S}$ & $\mathrm{Cr}$ & $\mathrm{Ni}$ & $\mathrm{Fe}$ \\
0.36 & 1.60 & $0 \cdot 27$ & 0.02 & 0.12 & 0.14 & $0 \cdot 11$ & Balance \\
\hline
\end{tabular}

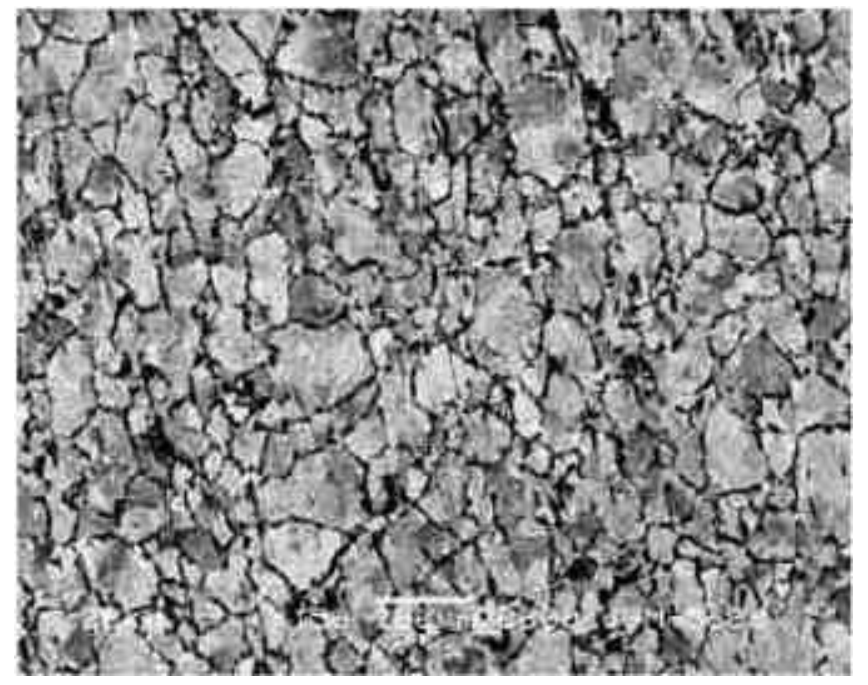

Figure 1. SEM micrograph of sample A showing ferritic phase of related steel in as received state.

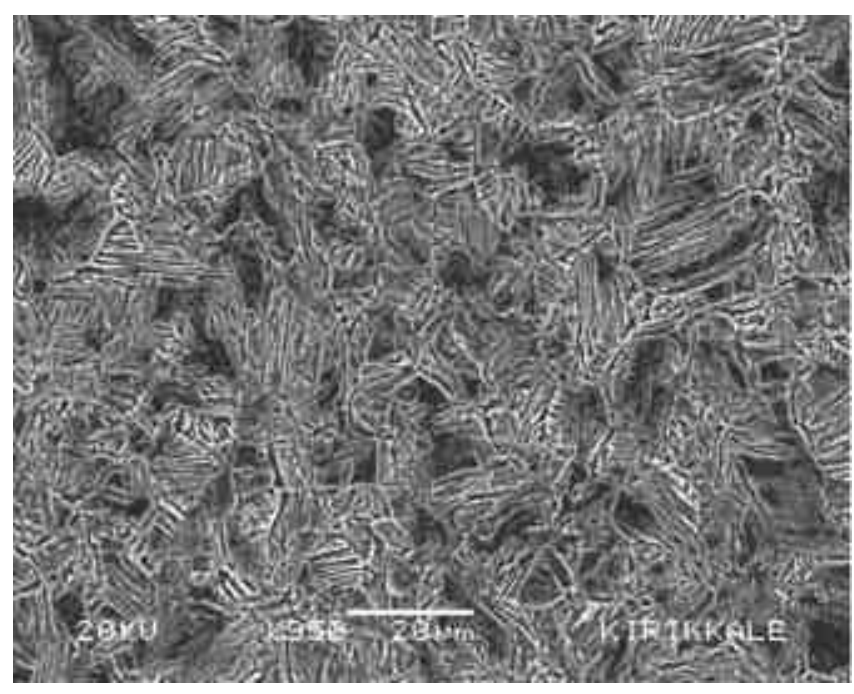

Figure 2. SEM micrograph of sample B showing lamellar characteristic of pearlite formation.

mechanically from the bulk specimens of samples B and C. These slabs were mechanically thinned to $\sim 50 \mu \mathrm{m}$ with $\mathrm{SiC}$ papers. After grinding, specimens were polished with a $3 \mu$ diamond paste and finally etched with $2 \%$ Nital for scanning electron microscopic (SEM) observations. SEM observations were performed by a JEOL-JSM-5600 type SEM operated at $20 \mathrm{kV}$.

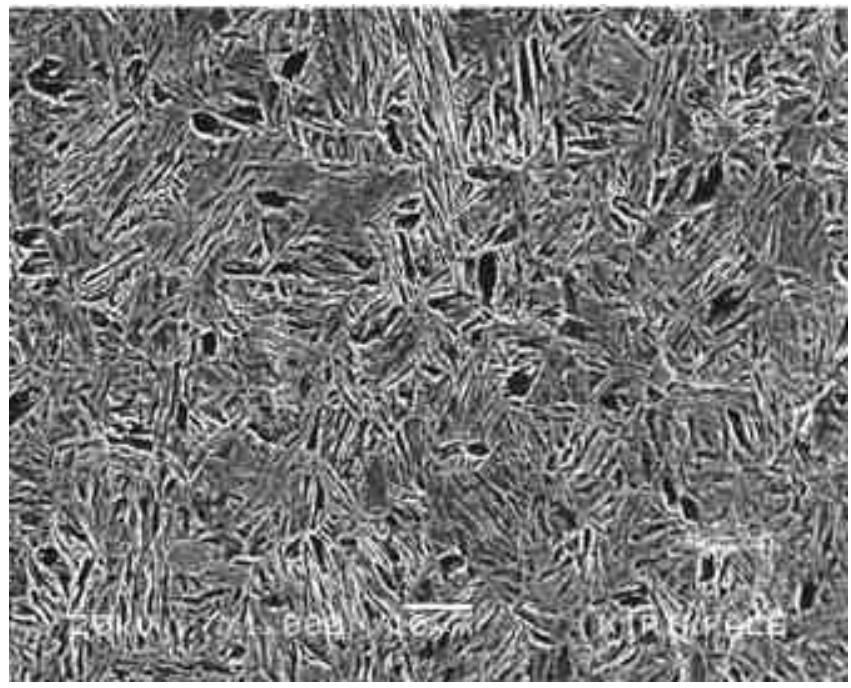

Figure 3. SEM micrograph of sample $\mathrm{C}$ showing needle-like lower bainite formation.

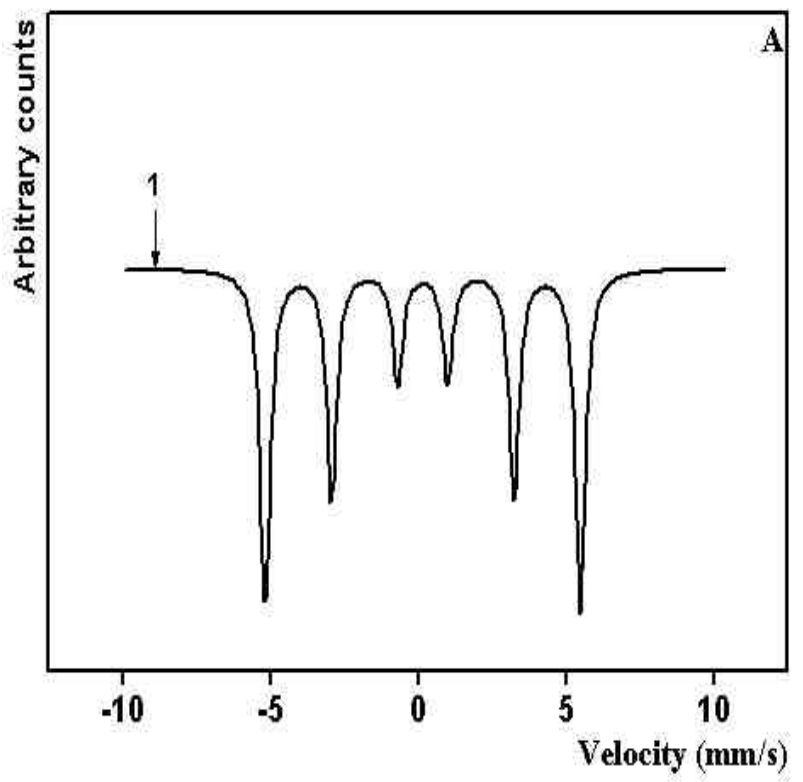

Figure 4. Mössbauer spectrum of sample A. Line 1 corresponds to a typical sextet of ferromagnetic ferrite phase.

\section{Results}

Equiaxed ferrite grains can be easily seen in figure 1 for sample A.

Figures 2 and 3 show pearlite formation for sample B and needle-like bainite formation for sample $\mathrm{C}$, respectively. 
Table 2. Some Mössbauer parameters for samples A, B and C.

\begin{tabular}{|c|c|c|c|c|c|}
\hline AISI 1137 & $\begin{array}{l}\text { IS for parent phases } \\
\left(\mathrm{mm} \cdot \mathrm{s}^{-1}\right) \pm 0 \cdot 01\end{array}$ & $\begin{array}{c}\text { IS for product } \\
\text { phases }\left(\mathrm{mm} \cdot \mathrm{s}^{-1}\right) \pm 0.01\end{array}$ & $\begin{array}{c}\text { Retained parent } \\
\text { phases (\% volume) }\end{array}$ & $\begin{array}{l}\text { Formation of product } \\
\text { phases (\% volume) }\end{array}$ & $B_{\mathrm{hf}}($ Tesla $)$ \\
\hline Sample A & $0 \cdot 14$ & - & 100 & - & 33.05 \\
\hline Sample B & $0 \cdot 10$ & $0 \cdot 20$ & $4 \cdot 4$ & $95 \cdot 6$ & $32 \cdot 70$ \\
\hline Sample C & $0 \cdot 21$ & 0.53 & $7 \cdot 2$ & $92 \cdot 8$ & $32 \cdot 60$ \\
\hline
\end{tabular}

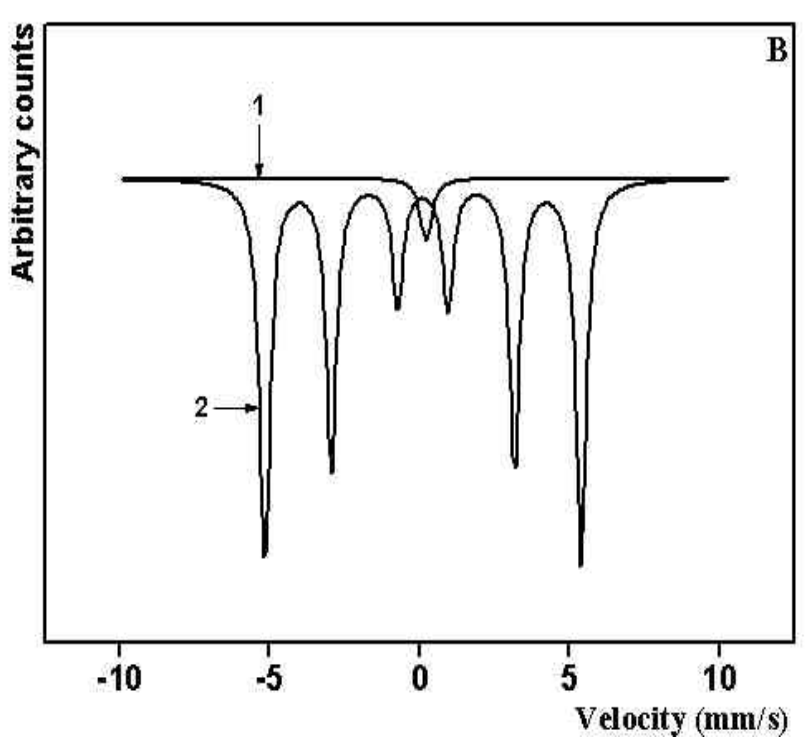

Figure 5. Mössbauer spectrum of sample B. Line 1 corresponds to parent phase whereas line 2 belongs to pearlite phase.

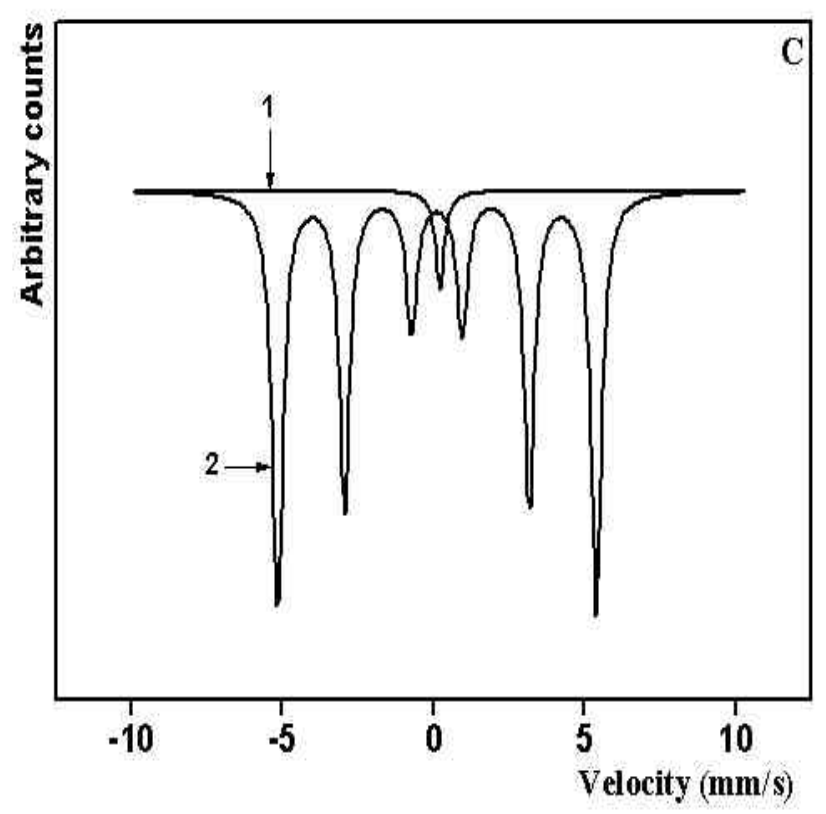

Figure 6. Mössbauer spectrum of sample C. Line 1 corresponds to parent phase whereas line 2 belongs to bainite phase.

After SEM observations, these thin foils were used for Mössbauer spectroscopy. The Mössbauer spectroscopy was carried out at room temperature by using $25 \mathrm{mCi}{ }^{57} \mathrm{Co}$ source diffused in Rh. Mössbauer spectra were calibrated with respect to $\alpha-\mathrm{Fe}$. The isomer shifts were given to the centre of the $\alpha$-Fe spectrum. A typical sextet for ferromagnetic ferrite phase of sample A can be easily seen in figure 4 . On the other hand, figures 5 and 6 show a singlet for parent phases and also a sextet for product phases of samples B and C.

Some Mössbauer parameters such as isomer shift (IS), \%volume transformation and hyperfine magnetic field $\left(B_{\mathrm{hf}}\right)$ of the ferrite, pearlite and bainite phases obtained from Mössbauer spectroscopy are given in table 2 .

\section{Conclusions}

From the above data, the following conclusions are drawn:

(I) The magnetism of ferrite in this steel is obtained as $33.05 \mathrm{~T}$ and it is higher than the magnetisms of both pearlite and bainite.

(II) Pearlite formation was observed from SEM investigations for sample B with a $32.7 \mathrm{~T}$ internal magnetic field and $95.6 \%$ transformation volume which are determined by Mössbauer spectroscopy for an AISI 1137 type steel.

(III) As Oka and Okamato (1995) pointed out, it is well known that there are two types of bainites such as a feathery upper bainite and a needle-like lower bainite. In this study a needle-like lower bainite is observed for related steel in sample $\mathrm{C}$ by SEM investigations with a $32.6 \mathrm{~T}$ internal magnetic field and $92.8 \%$ transformation volume which are also determined by Mössbauer spectroscopy.

(IV) Different processes such as different quenching media also exhibited different morphologies for the studied steel whose results are well in agreement with literature.

\section{References}

Bhadeshia H K D H 1992 Bainite in steels (London: Cambridge University Press)

Callister W D 2003 Materials science and engineering: An introduction (New York: John Wiley \& Sons Inc.) 6th ed

Enomoto M and Tsubakino H 1991 Mater. Trans. JIM 32642

Gavriljuk V G et al 2000 Scr. Mater. 43223

Gütlich P 1978 Mössbauer spectroscopy and transition metal chemistry (Berlin, Heidelberg: Springer-Verlag)

Haseeb A S M A et al 2001 Scr. Mater. 44519 
Moffat W G 1967 The structure and properties of materials (New York: John Wiley \& Sons Inc) Vol. 1

Nishiyama Z 1978 Martensitic transformation (New York: Academic Press)

Ohmori Y and Maki T 1991 Mater. Trans. JIM 32631
Oka M and Okamoto H 1995 J. Phys. 5503

Ou D R et al 2003 Mater. Sci. \& Technol. 1987

Thewlis G 2004 Mater. Sci. \& Technol. 20143

Umemoto M et al 1993 J. Mater. Sci. 182893

Xiaoyan S and Nanju G 1996 ISIJ Int. 36592 